\title{
Research on Product Technical Maturity Forecasting and R \& D strategy based on TRIZ
}

\author{
Changqing Gao, Jianhua Sun, Pengjie Zhai, Xiaowen Chi \\ School of Mechanical Engineering, University of Jinan, No.336 Nanxinzhuang West Road, Jinan, \\ Shandong, P.R.China
}

Keywords: Product maturity, TRIZ, Patent analysis, R \& D strategy

\begin{abstract}
For the enterprise in changeful market environment, product technical maturity is an important reference to develop strategies and hold technology trades. It is benefit to accurately determine the developmental level of relevant techniques and carry out technical innovation with scrutiny to situation. On the basis of two methods which Altshuller and Darrell Mann used to forecast maturity, synthesize the patent characteristic curve, this paper finished the product technical maturity forecasting. The analysis of technology maturity is the base for enterprise research and development strategy. The different R \& D strategy should be carried on according to the different stage of product life including Infancy stage, Growth stage, Maturation stage and Degeneration stage.
\end{abstract}

\section{Significance of product maturity forecasting}

In the modern social fierce competition, how to grasp the opportunity to forecast our product technical maturity becomes particular important. Product technical maturity is an important indicator that enterprise should consider when the strategy of produce development and technical innovation are made. It is also an important reference of technology trade and an important basis which some functional departments should refer to in the process of Technology research and development project. The process product technical maturity forecasting can help enterprises to seek own disparity, improve their technical level and look for innovations.

Product technical maturity forecasting means research the product as a technology system. By assessing the technology of current products, we can forecast the current products belong to which phases of technology life circle. The performance improvement of product family which is composed of products based on the same core technology meets the growths tend of S curve. If the best performance product in the product family has attained to recession of product technology evolution, the evolutionary curve which is formed by the existing products in the product family is a complete S curve ${ }^{[1-2]}$. Otherwise, this S curve is incomplete. But with further technical innovation and further investment, eventually a complete $S$ curve will form. Then the position of current product on the $S$ curve is product technical maturity. The process that determines the position of current products is called product technical maturity forecasting. S curve is shown in Fig. 1.

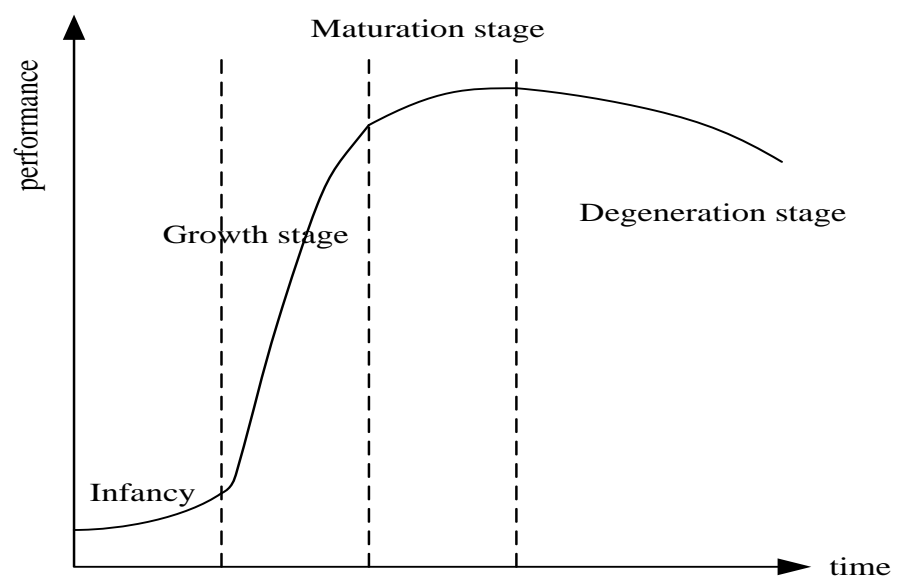

Fig.1: S curve of the technology system 


\section{The method of technical maturity forecasting}

\subsection{Theory of technical system evolution.}

The theory of technical system evolution is an important outcome of TRIZ theory, which includes two research contents. On the one hand is the research of product evolution process (including the research of product technical maturity forecasting). On the other hand is the research of technical evolutionary laws and lines.

TRIZ theory insists that all products are technical system in the evolution and evolution means technical performance parameters will be optimized. According to the technological development speed, we divide the development of product technologies into three stages: new invention stage, technological improvements stage, technological maturation stage [3].

We can see from the process of technical development that all product families develop according to the same evolution steps. They start with the discovery of technology and end with the extinction of technology following along the S curve. Discovery marks the beginning of product invention. Because of various reasons (investment risks, big technical flaws, enterprises lack of interest, etc), we will take many years even morn several decades to solve the main problem limit the new product family. Then products have the capability to enter the market. In the period from finding to products have the capability to enter the market, products performance have no capability to enter the market. Altshuller called this period infancy of product evolution.

In the process of technical system quickly improve performance, competitors begin to produce similar products. Competition among them promotes the development velocity of technical system. Product families in the market gradually flourish, and finally market is nearly saturated. Altshuller called this period that product performance quickly improved, growth stage.

As the development of technical system reaches its limits, the development velocity gradually slows down. But because of competitive requirements in competitors, enterprises continue to invest large sums money to compel technical system reach its limits. In this period, product performance basically reaches its limits and the cost also basically reaches its lowest. Altshuller called it maturation stage of produce evolution.

Once reached technical limits, all achievements of innovation efforts become smaller. At this point, enterprises maintain the market depend on market tools. On the other hand enterprises actively look for replacement technology and launch new products. This is the degeneration stage of product evolution.

\subsection{Level of invention.}

\begin{tabular}{|c|c|c|c|c|}
\hline $\begin{array}{l}\text { Level of } \\
\text { invention }\end{array}$ & $\begin{array}{l}\text { Changes of } \\
\text { system }\end{array}$ & $\begin{array}{l}\text { Amount of } \\
\text { optional } \\
\text { solutions }\end{array}$ & Knowledge used & Percentage \\
\hline 1 & $\begin{array}{l}\text { Compromise, } \\
\text { the quantitative } \\
\text { changes }\end{array}$ & Several & $\begin{array}{l}\text { Specialized } \\
\text { knowledge of } \\
\text { designers }\end{array}$ & $32 \%$ \\
\hline 2 & $\begin{array}{l}\text { Partly } \\
\text { qualitative } \\
\text { changes }\end{array}$ & Dozens & $\begin{array}{l}\text { Knowledge of } \\
\text { an industry(a } \\
\text { branch of } \\
\text { subjects) }\end{array}$ & $45 \%$ \\
\hline 3 & $\begin{array}{l}\text { Systemic } \\
\text { qualitative } \\
\text { changes } \\
\text { fundamentally }\end{array}$ & Hundreds & $\begin{array}{l}\text { Cross-industry } \\
\text { knowledge(other } \\
\text { branch of } \\
\text { subjects) }\end{array}$ & $19 \%$ \\
\hline 4 & $\begin{array}{l}\text { Create a new } \\
\text { system }\end{array}$ & Thousands & $\begin{array}{l}\text { Multidisciplinar } \\
\text { y(effect and } \\
\text { phenomenon) }\end{array}$ & $4 \%$ \\
\hline 5 & New discovery & Millions & New knowledge & $0.3 \%$ \\
\hline
\end{tabular}

When researching the patents, in order to balance the levels and influence of inventions, Altshuller distinguished the "difficult and easy" of inventions. He divided problems into five levels based on attempting times solved problems. Likewise, the solutions of correspondence problem are 
divided into five levels, it is also known as five grades, which is the level of inventions we often mentioned [4-5]. The levels of invention are shown in Table 1.

\subsection{Characteristic curve of patents.}

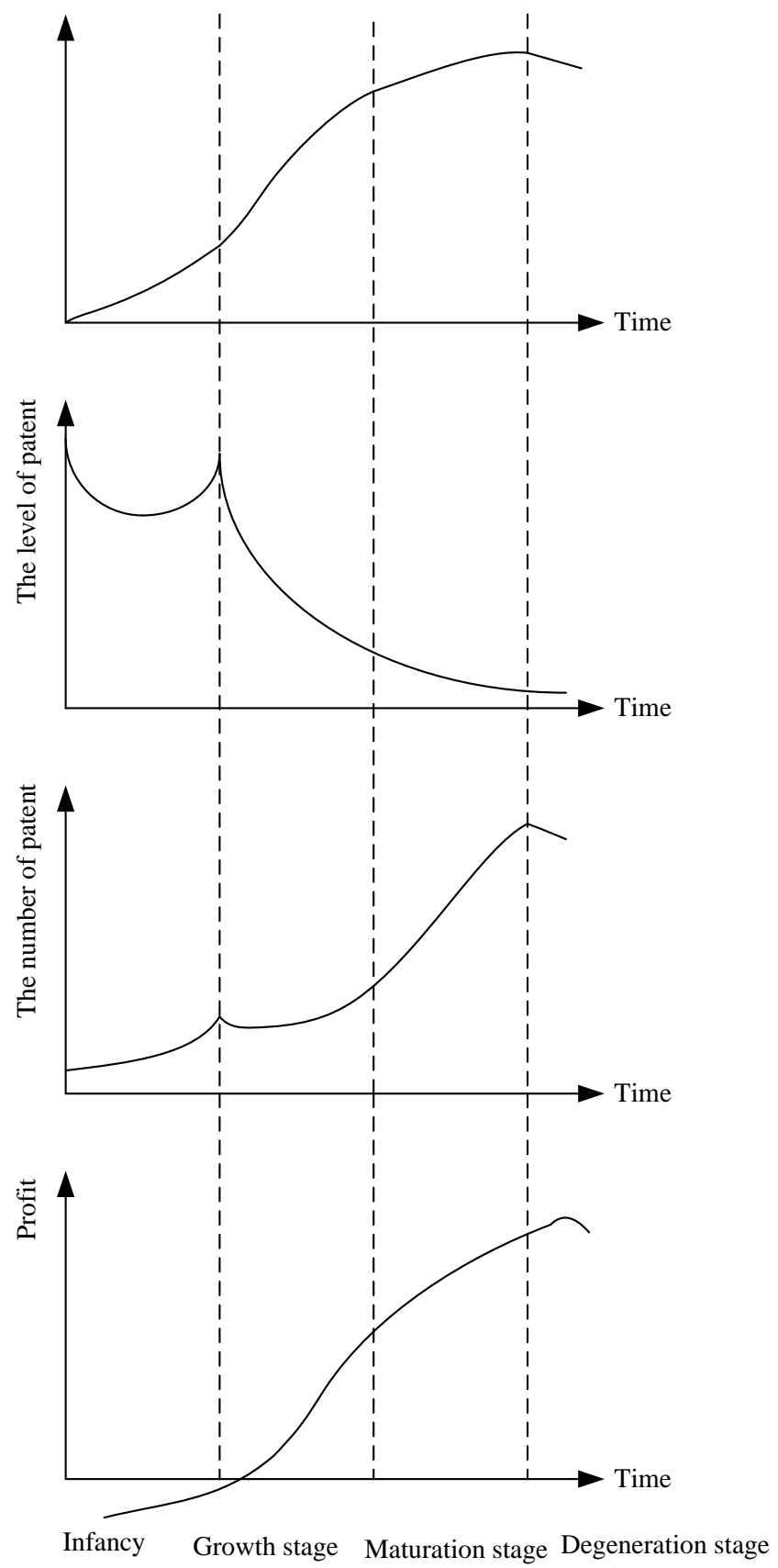

Fig.2: Character Curves

When examining the patent documents, Altshuller divided the level of invention into five grades according to the invention levels. When reviewing and categorizing the patents in researches, he found that the changes of patent grades are closely related to the process of technical system evolution. The process of technology development is generally expressed in S curve. Both growing process of technology and the relationship of patent level changes and technical system evolution process are expressed in piecewise linear S curve. Altshuller expressed how the patent levels change over time in the plane coordinate system. All the curve characters are shown in Fig. 2. 


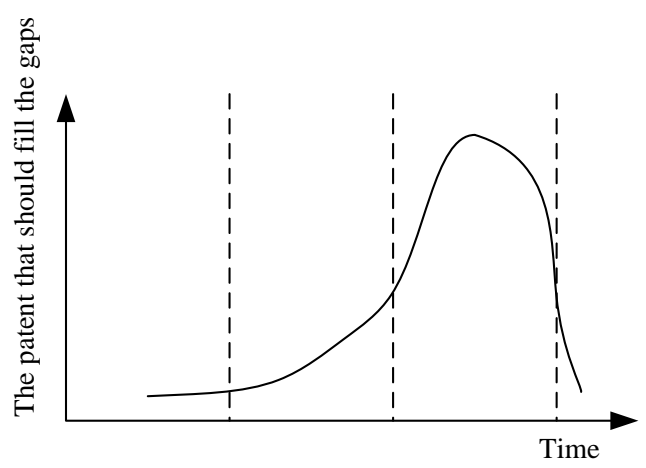

Fig.3: Patent that should fill the gaps

Darrell Mann was inspired from the examining mode Altshuller aimed to patents. Compared with the method of Altshuller, Darrel Mann mainly investigated two special kinds of patents. Patents could reduce costs and patents could fill the gaps. Its purpose is to improve the speed of patent investigation and easily generate patent investigation curve like the curve of Altshuller, thus quickly determine product technical maturity [6]. It is shown in Fig. 3.

\section{The process of technical maturity forecasting}

According to the relationship between the changes of patent characteristics and product technical maturity, we can forecast product technical forecasting. The process of product technical maturity forecasting using TRIZ theory is divided into the following six steps, including examine and refer to patent dates, Screen patent dates, Classify and grading the patent dates, Patent summarizing statistic, Generate the figure of S curve and Product maturity forecasting.

\subsection{Examine and refer to patent dates.}

First, we should retrieve the patent dates of subject we have selected. Nowadays network develops quickly, therefore there are many websites can be queried online. We can retrieve according to the retrieval knowledge we have learned, and those websites generally provide research function according to keywords. The patent related to the technology of one product could be retrieved through international patent classification and the characters included in patent name and abstract. It should be noted that we must figure out whether the technology whose name is different from this technology when searching one technology. If it really exists, we should retrieve this part dates.

\subsection{Screen patent dates.}

It is worth noting that the dates retrieved through keywords are not necessarily related to the technology we have researched. So if we want to analyze patent abstract, we just remove the unrelated contents. For example, we retrieve the patents of bus seats. But a large part of the patents retrieved through the keyword "seat" are not related to bus seats, such as car seats, truck seats. So we should screen these patent dates.

\subsection{Classify and grading the patent dates.}

After screening the patents, we can make grade for patents according to patent classification principles of Altshuller or their another method (the principle is the same).

\subsection{Patent summarizing statistic.}

Summarize patent dates year by year, make statistics of the number of patent in every stage time, the average rating of patents, the number of patents could fill the gaps, the number of patents could reduce costs and the patent situation from product appear to today.

\subsection{Generate the figure of $S$ curve.}

Generate time series according to statistics dates and begin to draw the $\mathrm{S}$ curve.

\subsection{Product maturity forecasting.}

Product maturity forecasting can be made based on the character curves. Comparing the standard curves with the curves for the current product, the stage of maturity can be determined. 


\section{Enterprise development strategy}

When the current technology system lies on the different stage of life maturity, the different research and development strategy should be taken. According to the characters of Infancy stage, Growth stage, Maturation stage and Degeneration stage, the investment and the focus of research and development for the product should be different in order to get the proper functions for the market requirements. There are Partial innovation, Partial innovation, mainly systemic innovation with partial innovation and Systemic innovation strategy [7-9]. As shown in Table 2.

Table 2 The strategies that enterprises should take in every stage of technical system evolution

\begin{tabular}{|c|c|c|}
\hline $\begin{array}{l}\text { Product technical } \\
\text { maturity }\end{array}$ & Enterprise technology strategy & Innovation strategy \\
\hline Infancy & $\begin{array}{l}\text { Assess the function capability of } \\
\text { this technology, if it is better than } \\
\text { the existing technology, we should } \\
\text { analyze the main barrier to } \\
\text { transformation from technology to } \\
\text { product and invest money. } \\
\text { Realizing the transformation from } \\
\text { technology to product and from } \\
\text { product to market as soon as } \\
\text { possible, we can seize the } \\
\text { technology leadership. }\end{array}$ & Partial innovation \\
\hline Growth stage & $\begin{array}{l}\text { First we get the new products to } \\
\text { market to seize the first-mover } \\
\text { advantages. Then constantly } \\
\text { improve the new products and } \\
\text { launch products more efficient } \\
\text { based on the core technology. } \\
\text { Finally we should enable the main } \\
\text { performance indexes (performance } \\
\text { parameters, efficiency, reliability, } \\
\text { etc) to be optimized to end of the } \\
\text { growth stage. }\end{array}$ & Partial innovation \\
\hline Maturation stage & $\begin{array}{l}\text { Improve technology, material, } \\
\text { appearance and minimize the costs } \\
\text { as soon as possible. In this period, } \\
\text { profit is obtained by marketing tool. } \\
\text { At the same time we should invest } \\
\text { money to track or explore possible } \\
\text { replacement technology, and judge } \\
\text { the product technical maturity of } \\
\text { new techniques, then take } \\
\text { corresponding countermeasures. }\end{array}$ & $\begin{array}{l}\text { Mainly systemic } \\
\text { innovation, partial } \\
\text { innovation }\end{array}$ \\
\hline $\begin{array}{l}\text { Degeneration } \\
\text { stage }\end{array}$ & $\begin{array}{l}\text { Again, invest money to seek, select } \\
\text { and research replacement } \\
\text { technology that could further } \\
\text { improve the product performance. }\end{array}$ & $\begin{array}{l}\text { Systemic } \\
\text { innovation }\end{array}$ \\
\hline
\end{tabular}

\section{Conclusions}

(1) Innovation is an important mean to improve our competitiveness and the enterprise without innovation will lose vigor. In the market environment, under competition pressure, enterprise constantly increase input to technology innovation. 
(2) The product technical maturity forecasting based on TRIZ can offer help to solve these two problems. The results of forecasting can help enterprises to grasp the innovation opportunity, and the process of forecasting can help enterprises to look through the technology development process, to find the rule of technology evolution. The technical maturity forecasting of Altshuller and Darrell Mann are set up on the basis of patent analysis, so their objectivity is better. Their forecasting results have reference value to enterprises.

\section{Acknowledgements}

This work was financially supported by Science and Technology Development Plan Project of Shandong Province (2014GGX106003), Large Equipment Upgrade Project of Shandong Province (2012SJGZ15).

\section{References}

[1] VICTOR F, EUGENE R, Innovation on De-mand, Cambridge: Cambridge University Press, 2007

[2] Semyon D. Savransky, Engineering of creativity, Florida: CRC Press, 2000

[3] TAN Runhua, ZHANG Huangao. Interactive Training Model of TRIZ for Mechanical Engineers in China. Chinese Journal of Mechanical Engineering, 27(2), pp. 240-248, 2014.

[4] ZHANG Jianhui, TAN Runhua, ZHANG Peng. Process Model of New Ideas generation for Product Conceptual Design Driven by CAI. Computer Intergrated Manufacturing Systems, 19(2), pp.284-292, 2013.

[5] ZHANG Huangao. The Technology of Mapping Technology Maturity of Product based on Patent Analysis and its Software Development. Tianjin: Hebei University of Technology, 2003

[6] ZHANG Fuying, ZHANG Linjing, WANG Ping. Study on Product Innovative Design Based on TRIZ Evolution Theory. Transactions of the Chinese Society for Agricultural Machinery, 39 (2) , pp.116-119, 2008.

[7] Darrell Mann. Using S-Curves and Trends of Evolution in R\&D Strategy Planning, 1997.7, http://www.triz-journal.com

[8] Genrich Altshuller. The Innovation Algorithm. New York: Technical Innovation Center, Inc. 2000

[9] JIANG Ping, LUO Pingya, SUN Jianguang. Method about Patent Design Around Based on Function Trimming. Journal of Mechanical Engineering, 8 (11) ,46-54, 2012. 